Supplement of Atmos. Chem. Phys., 18, 15307-15327, 2018

https://doi.org/10.5194/acp-18-15307-2018-supplement

(c) Author(s) 2018. This work is distributed under

the Creative Commons Attribution 4.0 License.

(c) (1)

Supplement of

\title{
Top-down estimates of black carbon emissions at high latitudes using an atmospheric transport model and a Bayesian inversion framework
}

Nikolaos Evangeliou et al.

Correspondence to: Nikolaos Evangeliou (nikolaos.evangeliou@ nilu.no)

The copyright of individual parts of the supplement might differ from the CC BY 4.0 License. 

(YEARS 2013-2015)
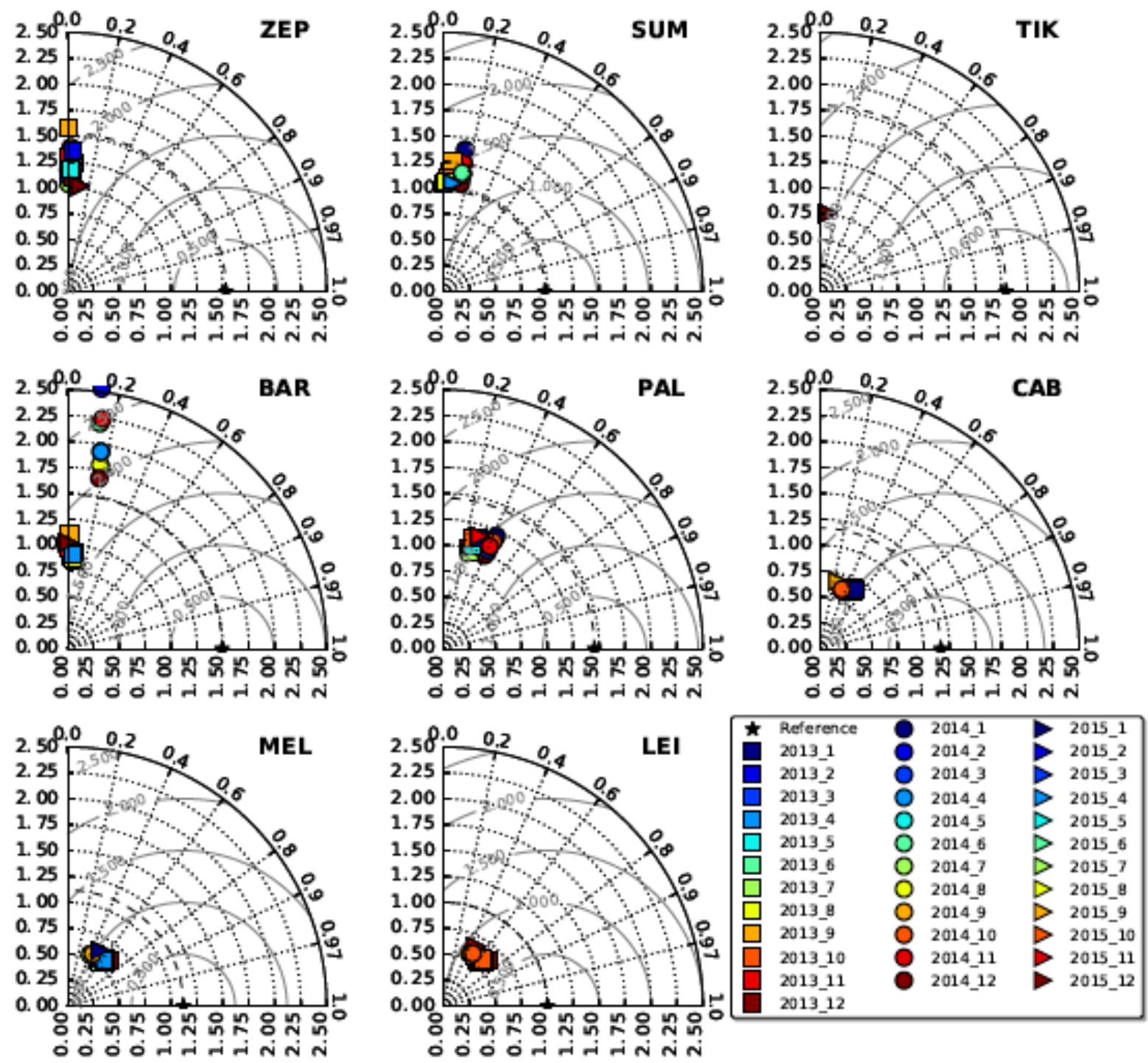

Figure S 1. Taylor diagrams for the comparison of the prior simulated concentrations with observations for all years $(2013$ - 2015) for 12 BC species with different scavenging coefficients (Table 2). The radius indicates standard deviations normalised against the mean concentration (NSD); the azimuthal angle the Pearson correlation coefficient, while the normalised (against observation) root mean square error (nRMSE) in the simulated concentrations is proportional to the distance from the point on the $\mathrm{x}$-axis identified as "reference" (grey contours). The results refer to the use of ACCMIPv5, EDGAR_HTAPv2.2 and MACCity as the prior emissions. 
(YEARS 2013-2015)
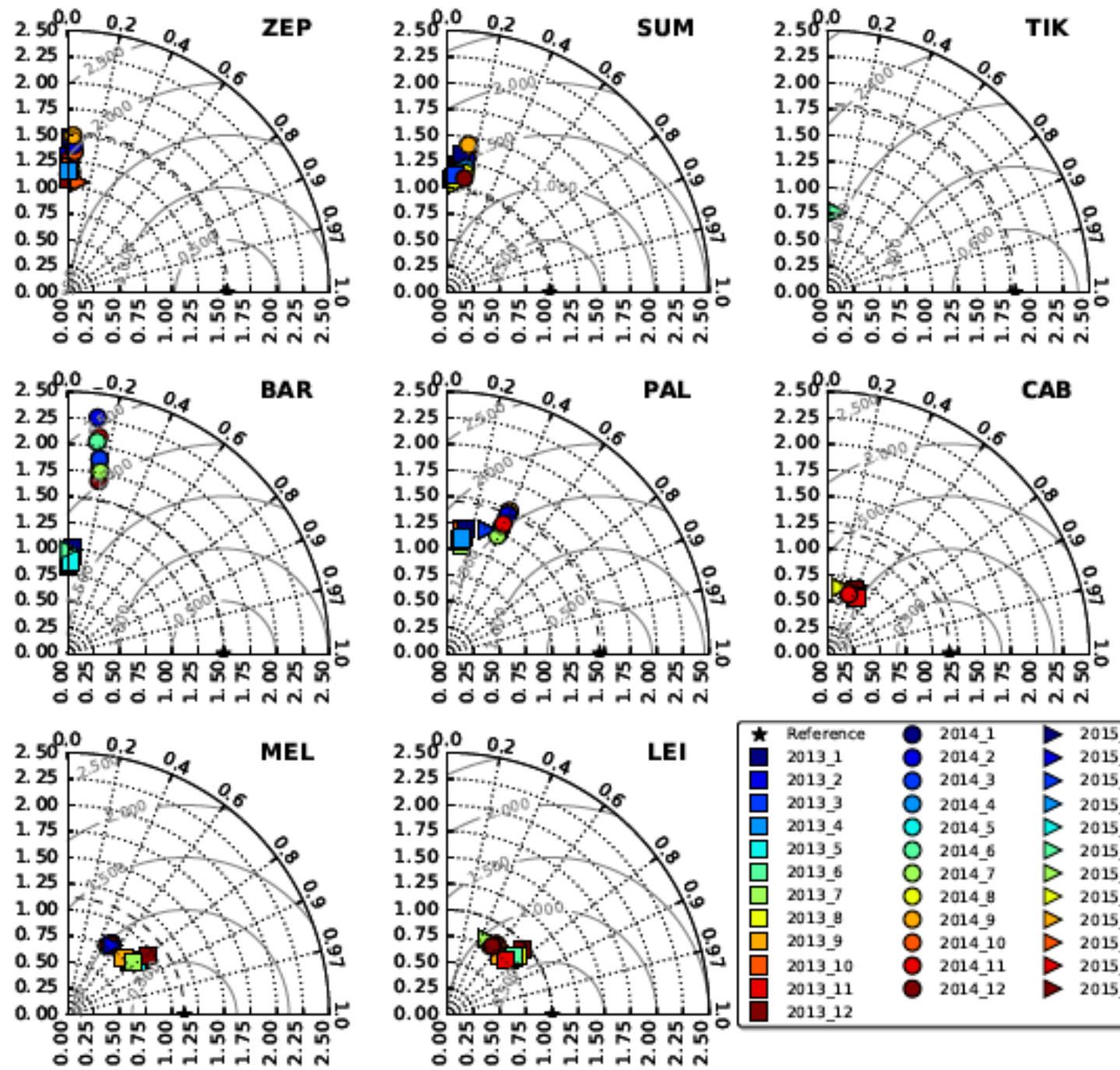

\begin{tabular}{|c|c|c|c|}
\hline$\star$ & Reference & 2014_1 & 2015_1 \\
\hline & 2013_1 & 2014 _2 & 2015_2 \\
\hline & 2013_2 & 2014 3 & 2015_3 \\
\hline & 2013 3 & 2014 _4 & 2015_4 \\
\hline ㄴ & 2013 _4 & $2014 \_5$ & 2015 _5 \\
\hline 들 & 2013 _5 & $2014{ }^{6}$ & 2015 -6 \\
\hline 담 & 2013 -6 & 20147 & 2015_7 \\
\hline 늘 & 2013 - ${ }^{2}$ & 2014 & 2015_8 \\
\hline & 2013_8 & 2014 & 2015_9 \\
\hline ᄃ & $2013 \_9$ & 2014_10 & 2015_10 \\
\hline & 2013_10 & 2014_11 & 2015_11 \\
\hline & 2013_11 & 2014_12 & 2015_12 \\
\hline & 2013_12 & & \\
\hline
\end{tabular}

Figure S 1. Continued 


\section{COMPARISON OF PRIOR SIMULATED CONCENTRATIONS (MACCITY) (YEARS 2013-2015)}
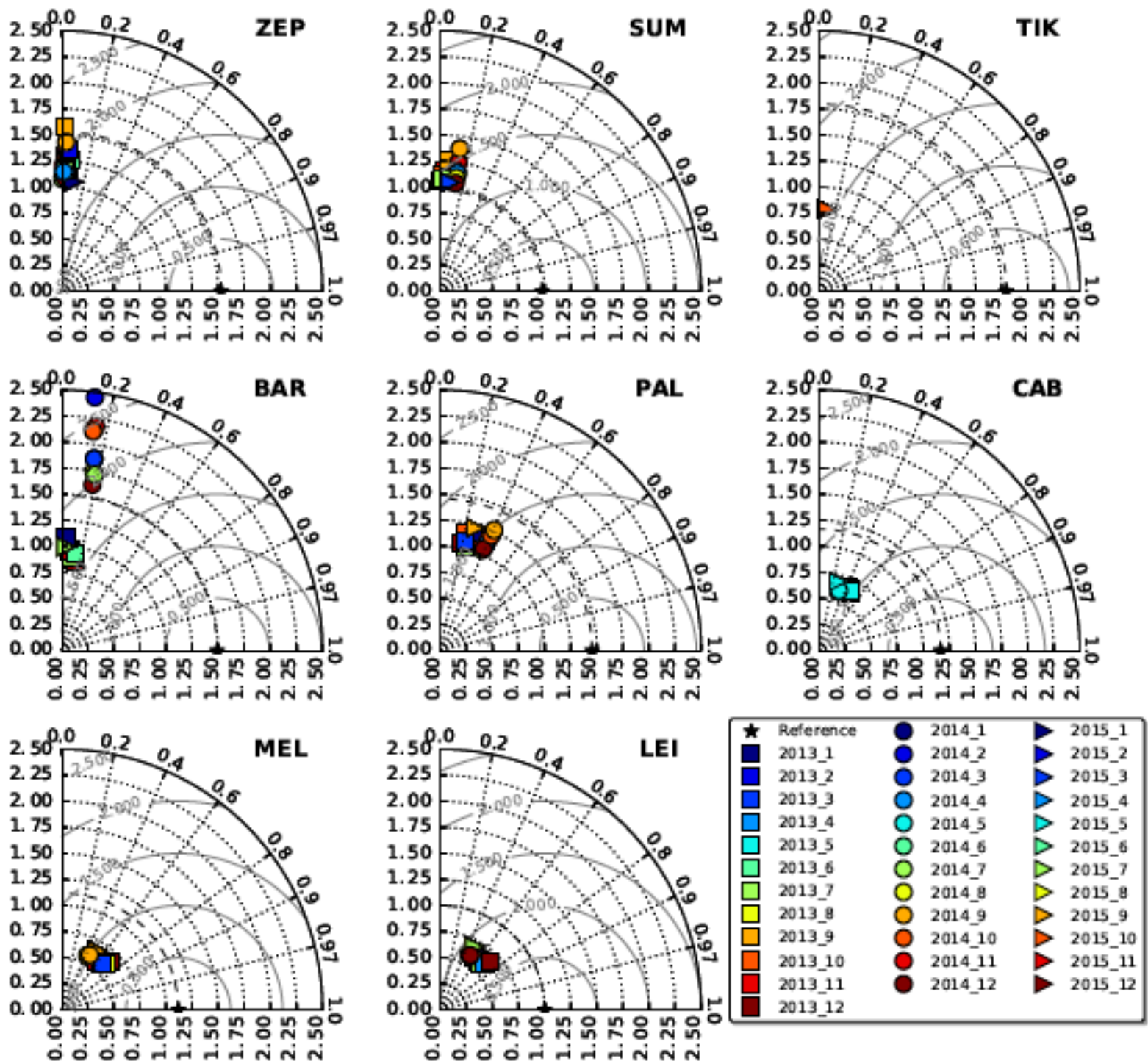

Figure S 1. Continued 


\section{MONTHLY AVERAGE MODEL-OBSERVATION MISMATCHES FOR 12 BC SPECIES (2013)}
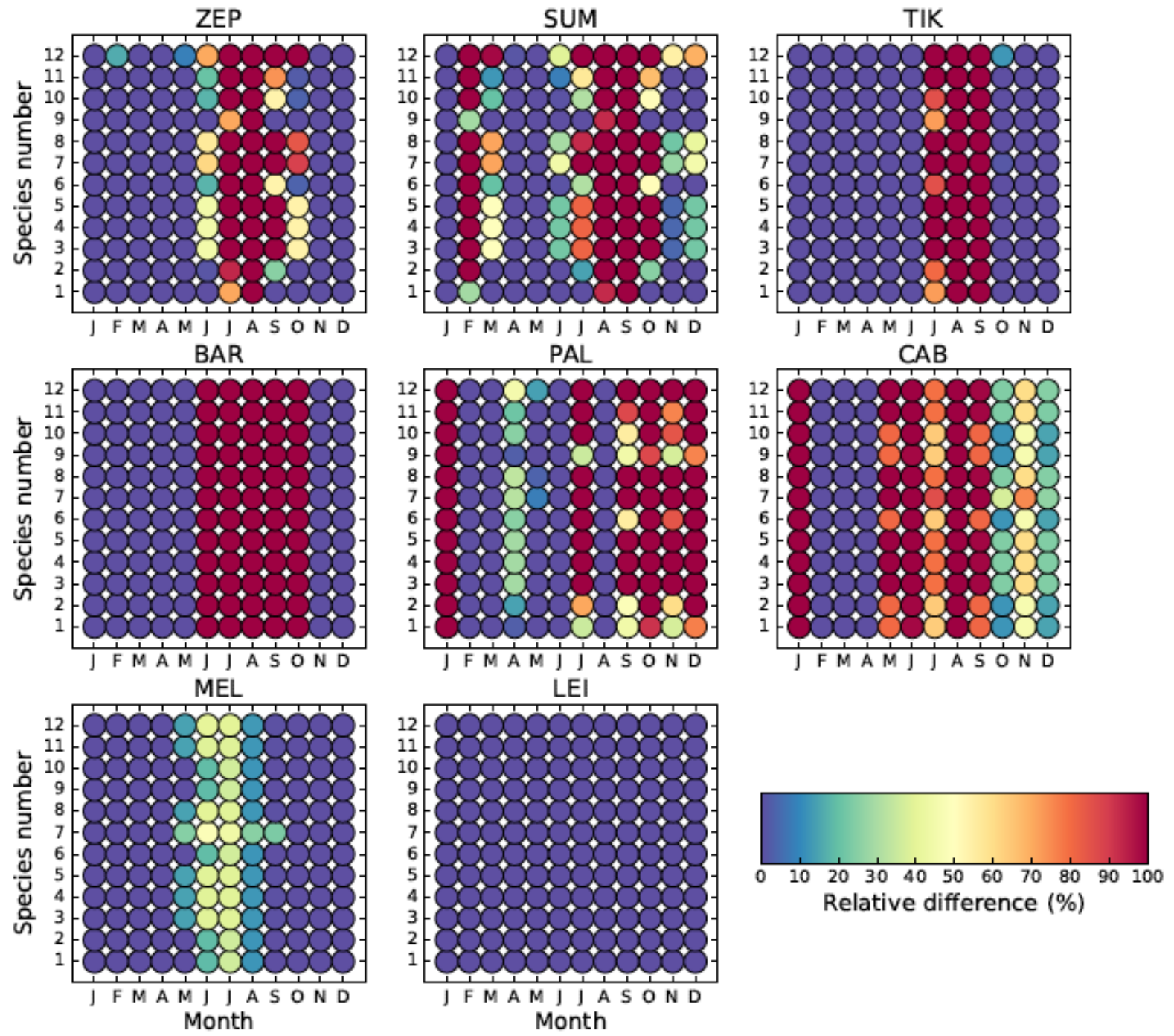

Figure $\mathbf{S}$ 2. Monthly average relative model-observation mismatches ([model-observations]/observations) for prior simulated (average values from all four inventories used) concentrations of $\mathrm{BC}$ due to the perturbation of scavenging parameters according to Table 2 for the inversions of 2013, 2014 and 2015. 
MONTHLY AVERAGE MODEL-OBSERVATION MISMATCHES FOR 12 BC SPECIES (2014)
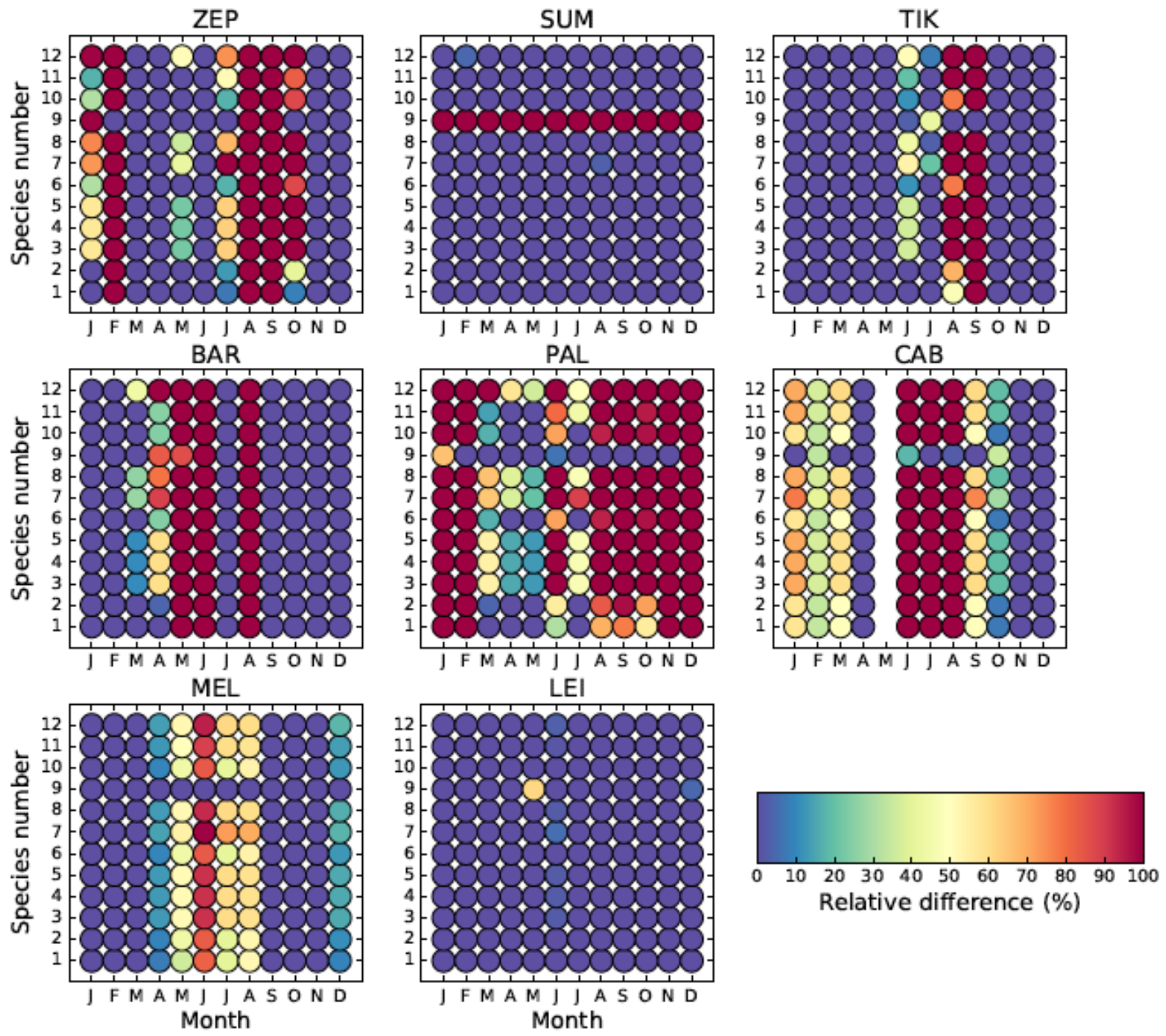

Figure S 2. Continued 


\section{MONTHLY AVERAGE MODEL-OBSERVATION MISMATCHES}

FOR 12 BC SPECIES (2015)
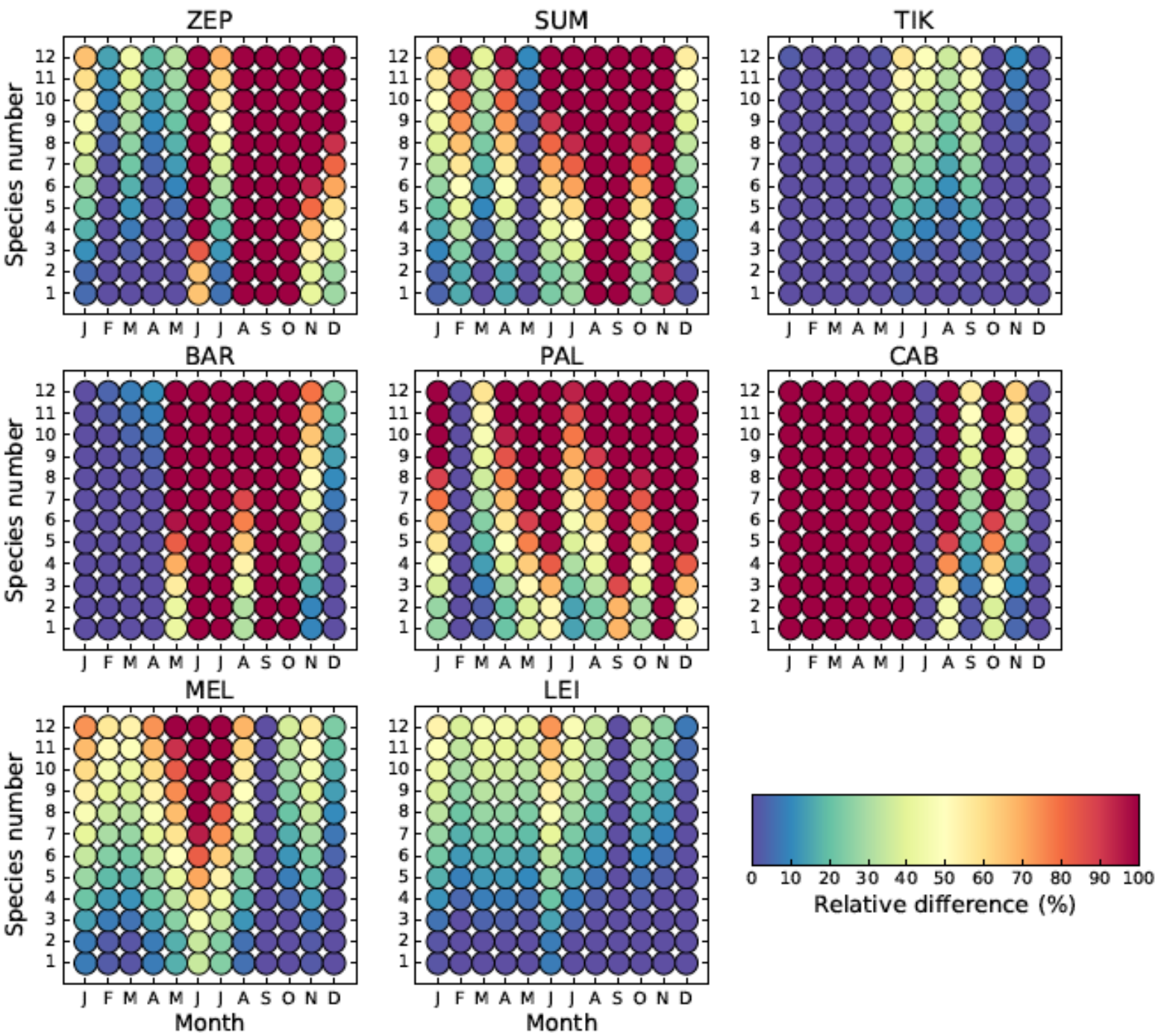

Figure S 2. Continued. 


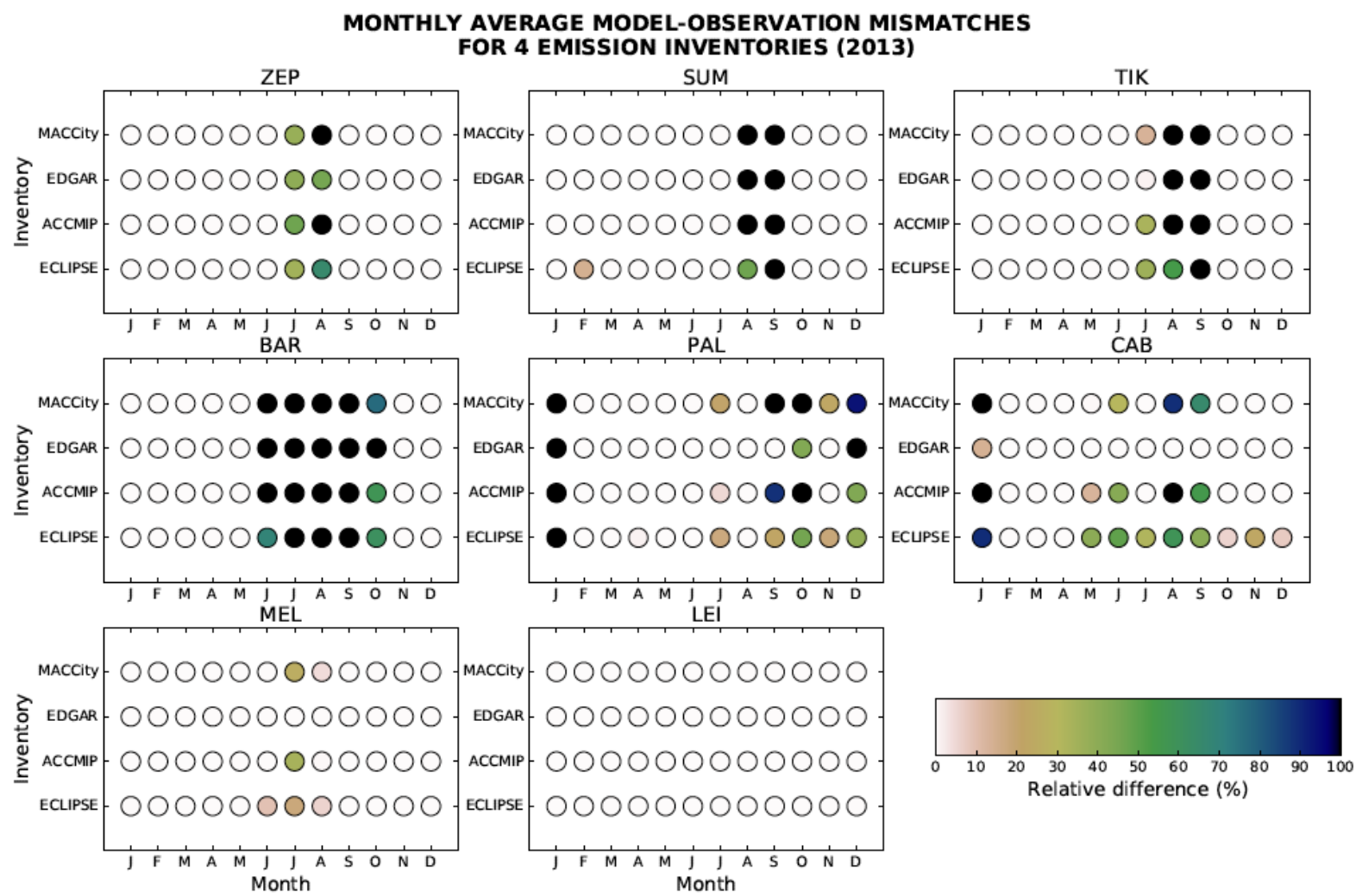

Figure S 3. Monthly average model-observation mismatches ([model-observations]/ observations) for prior simulated concentrations of $\mathrm{BC}$ (best species) due to use for four different emission inventories (ECLIPSEv5, ACCMIPv5, EDGAR_HTAPv2.2 and MACCity) for the inversions of 2013, 2014 and 2015. 


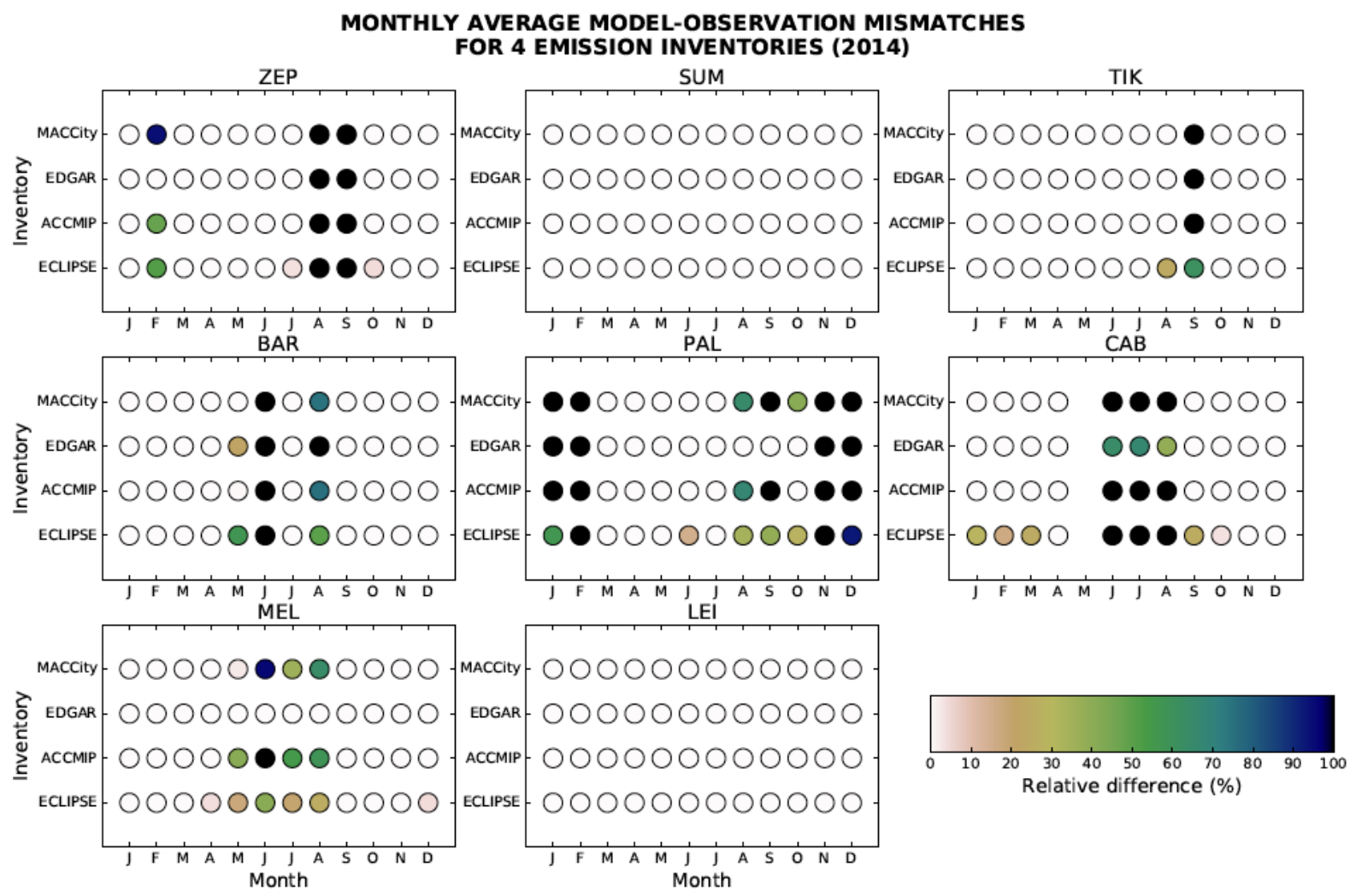

Figure S 3. Continued. 


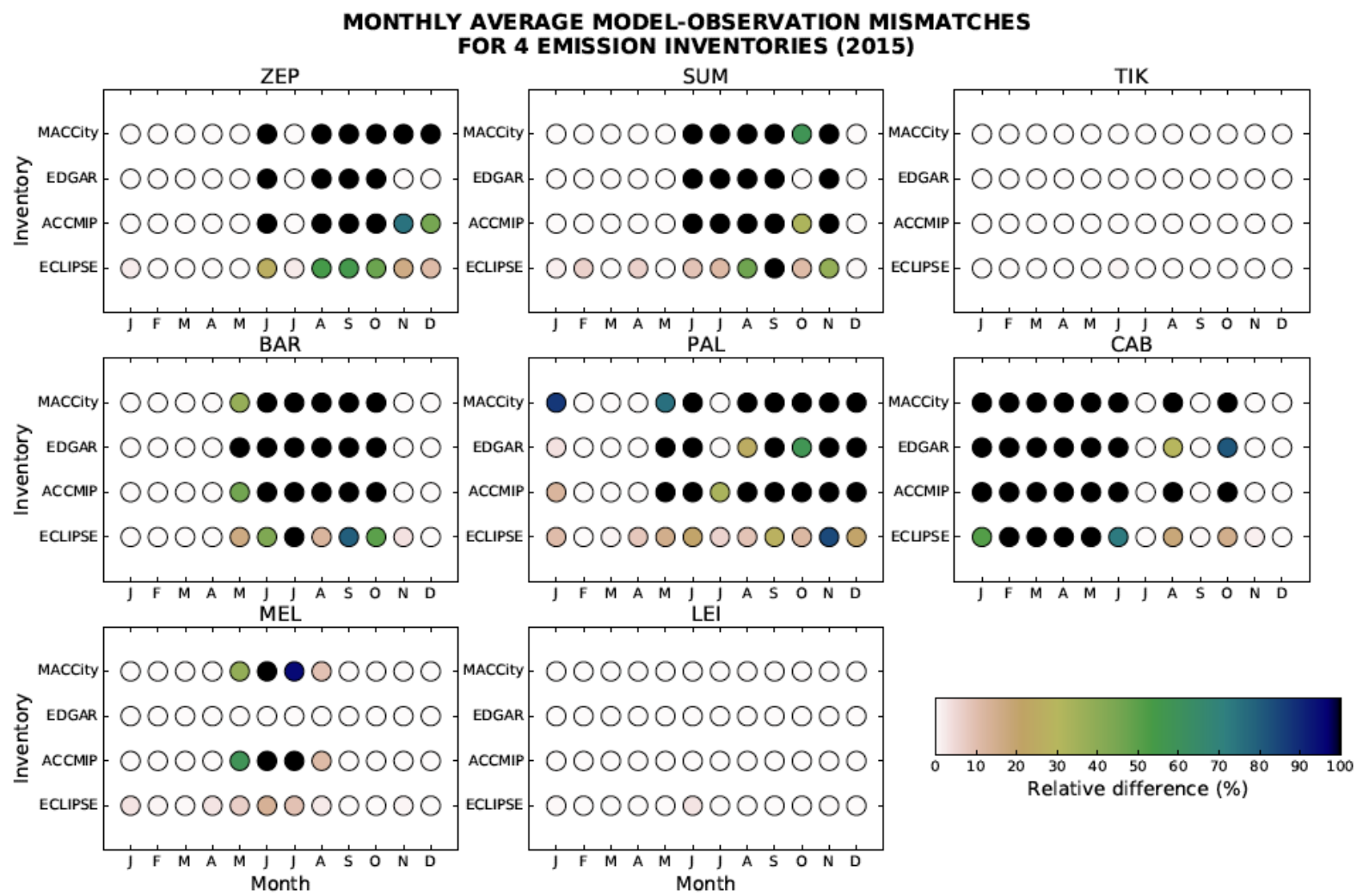

Figure S 3. Continued. 


\section{COMPARISON OF POSTERIOR SIMULATED CONCENTRATIONS (YEARS 2013-2015)}
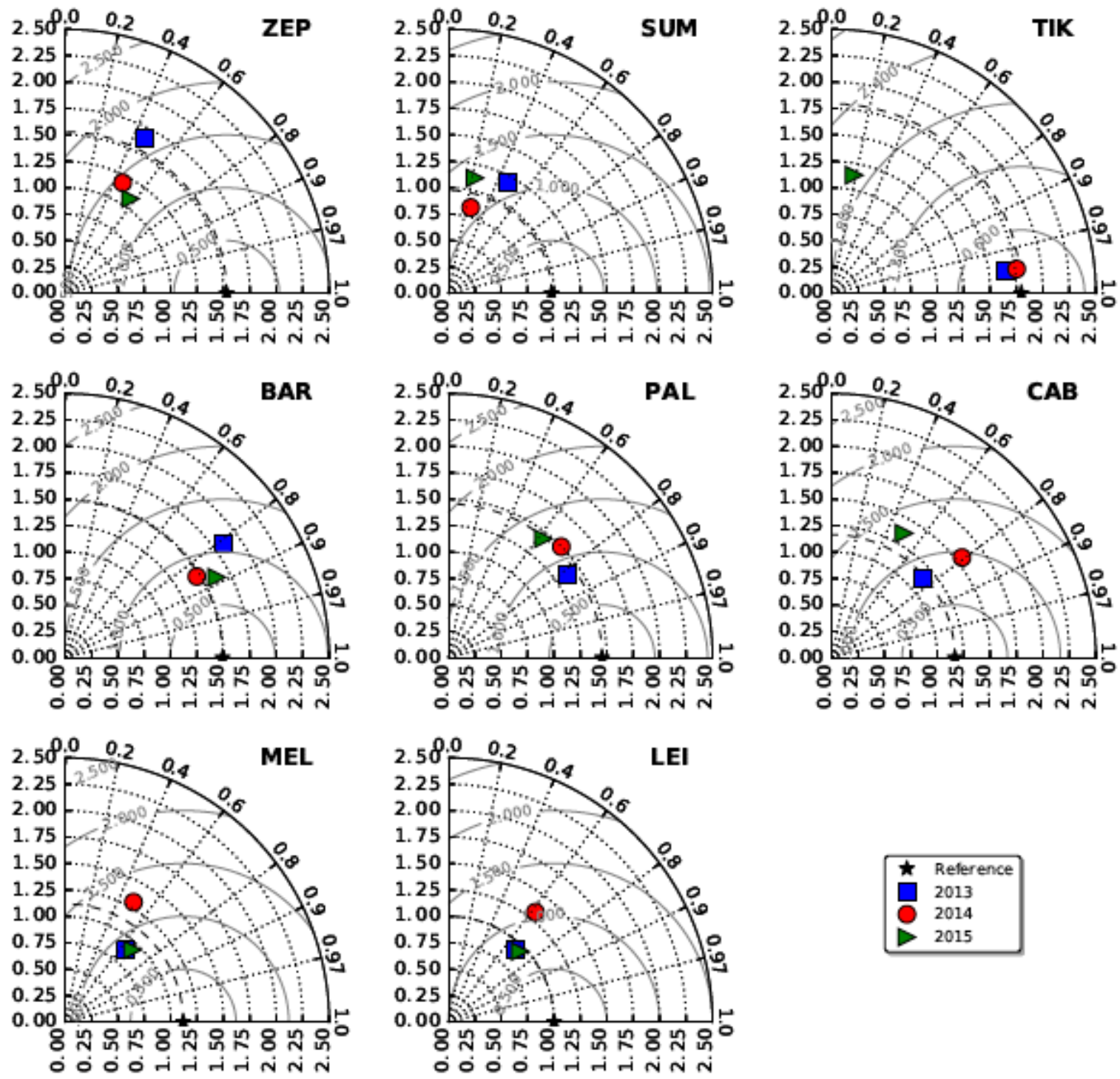

Figure S 4. Taylor diagrams for the comparison of the posterior simulated concentrations with observations for all years $(2013$ - 2015). The radius indicates standard deviations normalised against the mean concentration (NSD); the azimuthal angle the Pearson correlation coefficient, while the normalised (against observation) root mean square error (nRMSE) in the simulated concentrations is proportional to the distance from the point on the $\mathrm{x}$-axis identified as "observed" (grey contours). 
(a) Posterior emissions 2013

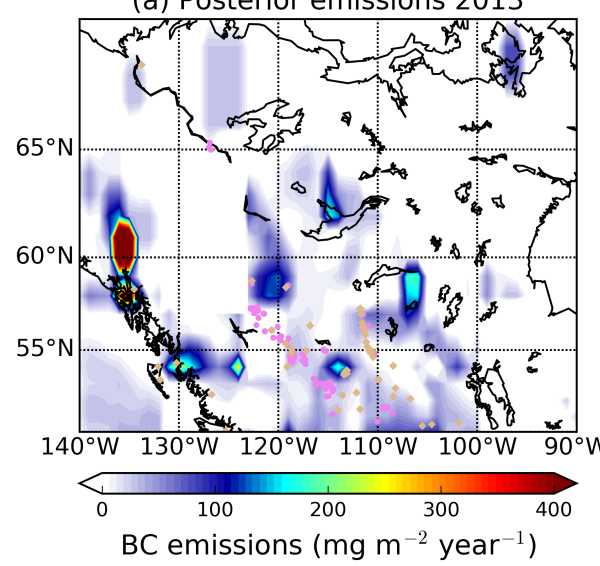

(c) Posterior emissions 2014

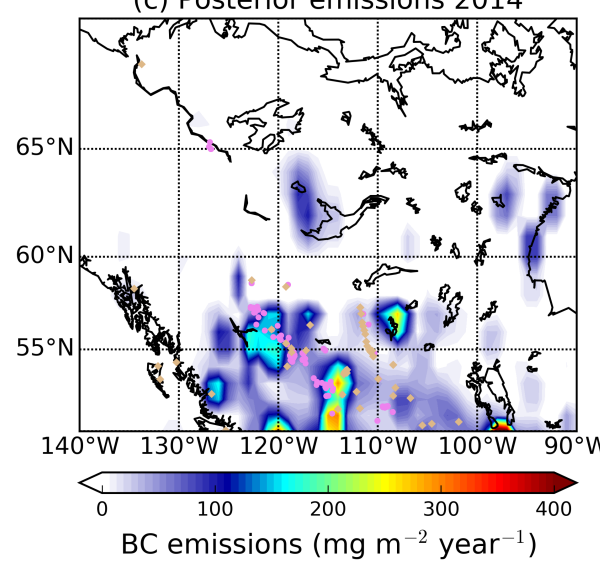

(e) Posterior emissions 2015

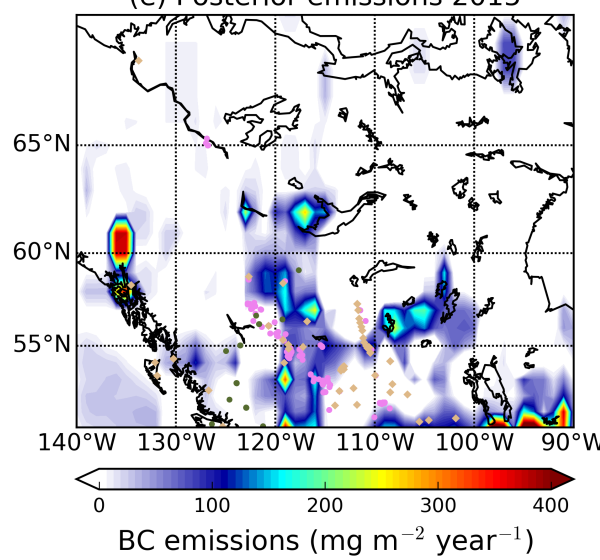

(b) Posterior-prior emissions 2013

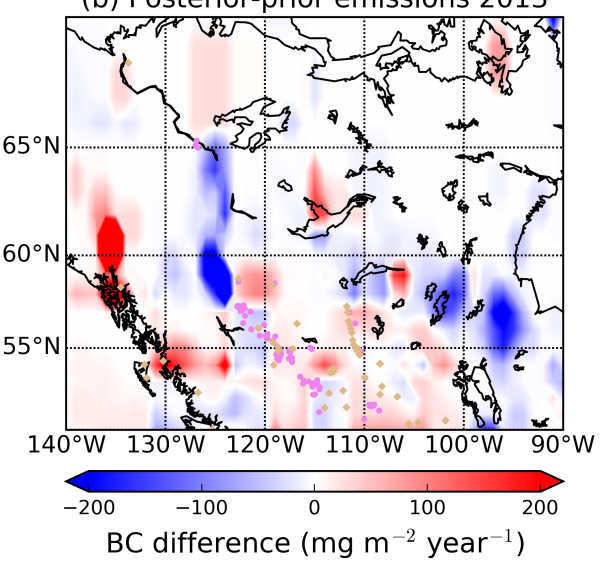

(d) Posterior-prior emissions 2014

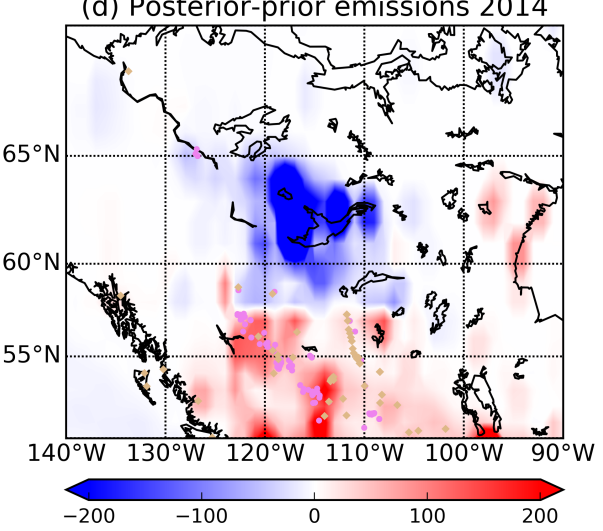

BC difference $\left(\mathrm{mg} \mathrm{m}^{-2}\right.$ year $\left.^{-1}\right)$

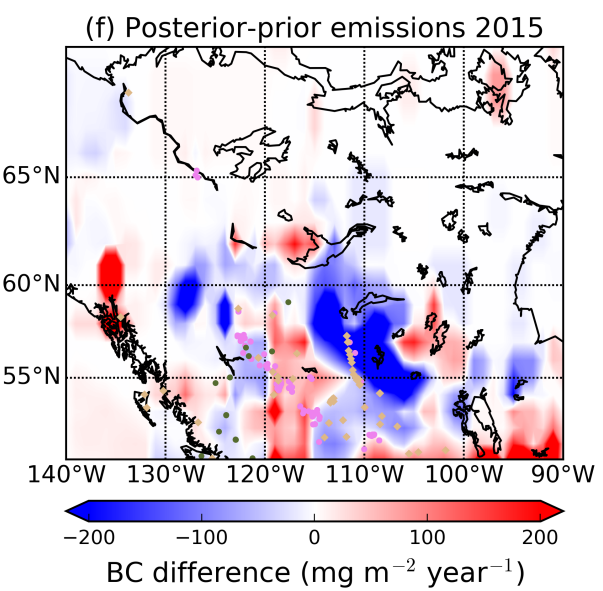

Figure S 5. (a, c, e) Optimised emissions of BC in North America (Western Canada) for 2013, 2014 and 2015. (b, d, f) Difference between a posteriori and a priori emissions of BC (ECLIPSEv5 was used as the prior). Magenta points on the map denote the gas flaring industries from the Global Gas Flaring Reduction Partnership (GGFR) (http://www.worldbank.org/en/programs/gasflaringreduction), grey points show the power industries that operate using fossil fuels and oil and gas production and oil refining industries adopted from Industry About (https://www.industryabout.com/canada-industrial-map), while dark green points show active fires from MODIS. 

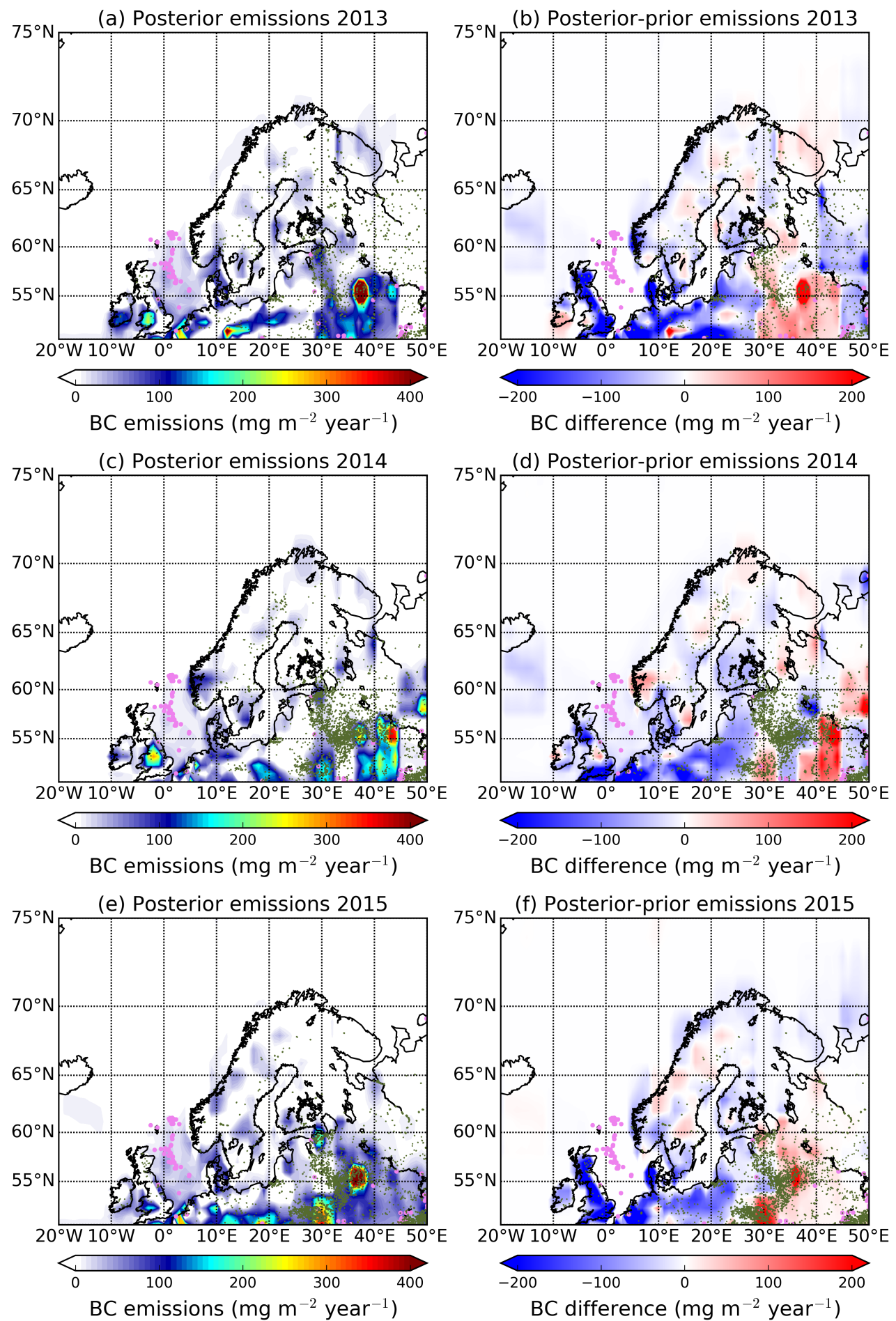

Figure S 6. (a, c, e) Optimised emissions of BC in Northern Europe for 2013, 2014 and 2015. (b, d, f) Difference between a posteriori and a priori emissions of BC (ECLIPSEv5 was used as the prior). Magenta points on the map indicate the gas flaring industries from the Global Gas Flaring Reduction Partnership (GGF) (http://www.worldbank.org/en/programs/gasflaringreduction), while dark green points show vegetation fires adopted from Hao et al. (2016). 
(a) Posterior emissions 2013
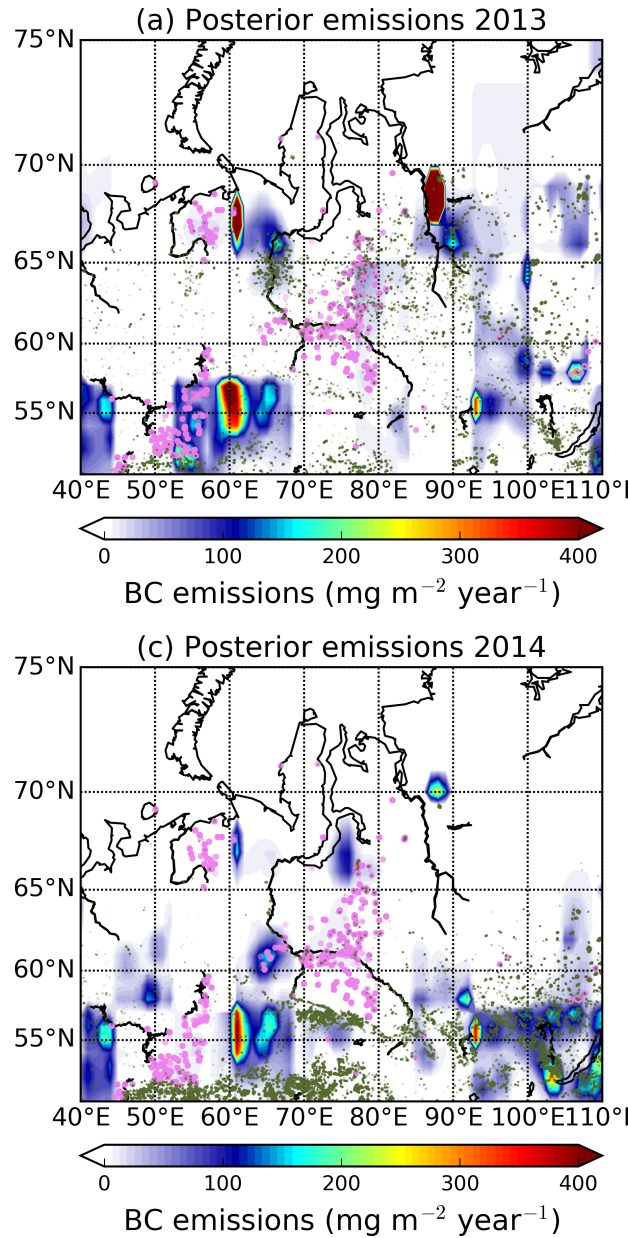

(e) Posterior emissions 2015

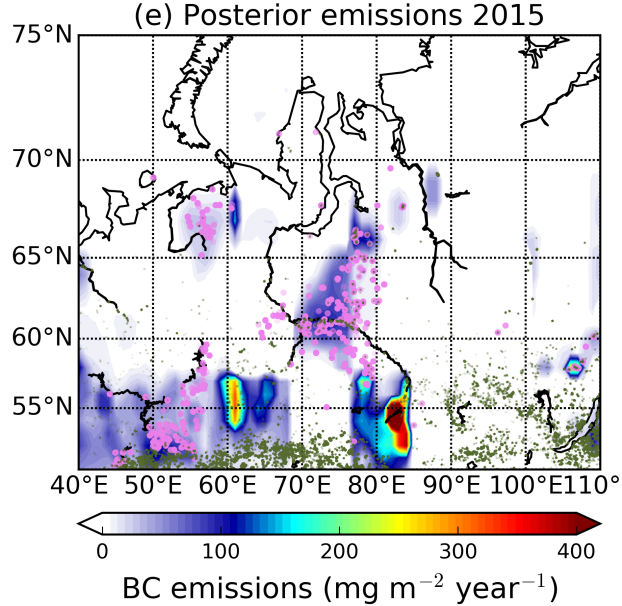

(b) Posterior-prior emissions 2013

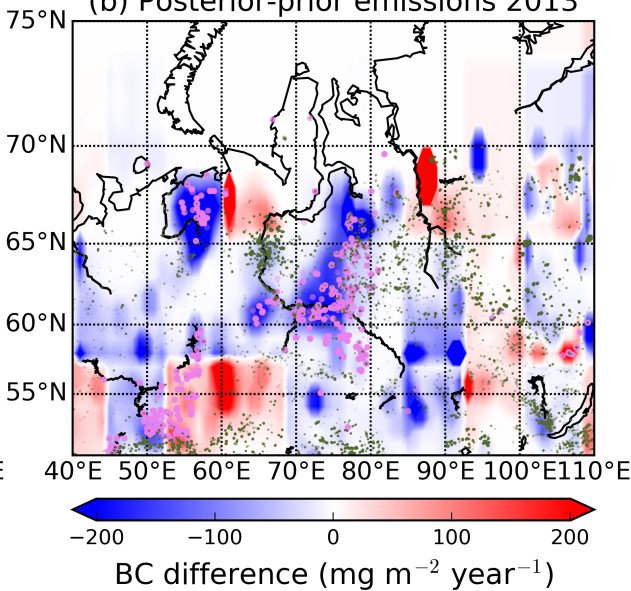

(d) Posterior-prior emissions 2014
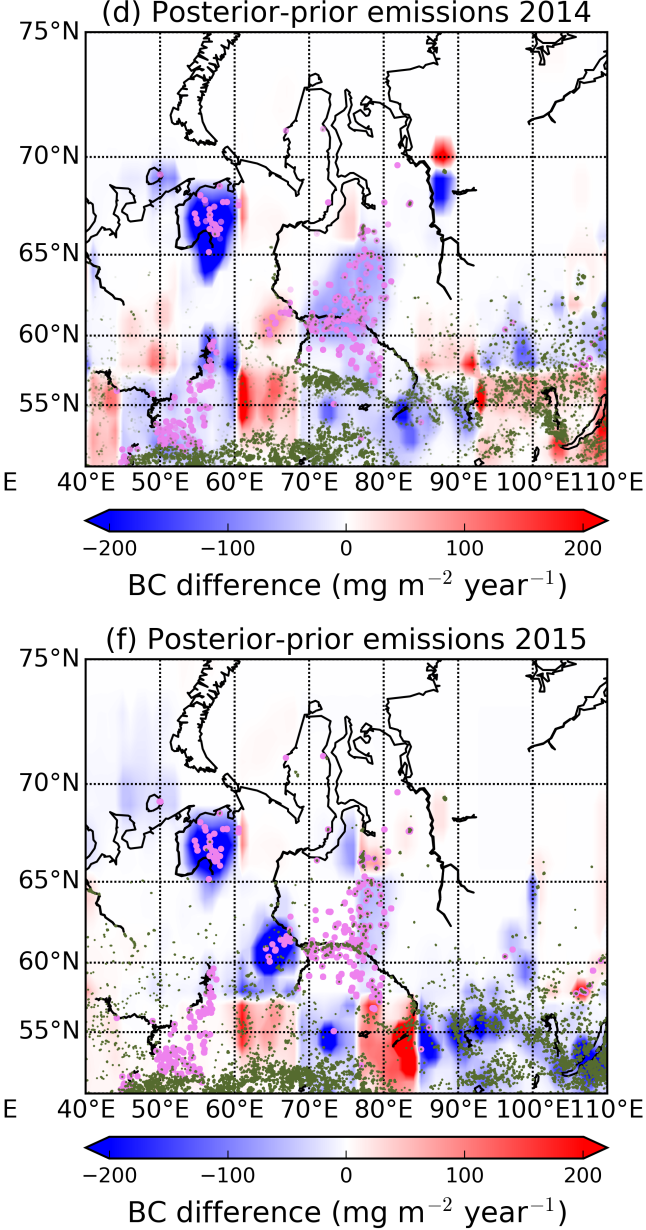

Figure S 7. (a, c, e) Optimised emissions of BC in Western Siberia for 2013, 2014 and 2015. (b, d, f) Difference between a posteriori and a priori emissions of BC (ECLIPSEv5 was used as the prior). Magenta points on the map indicate the gas flaring industries from the Global
Gas
Flaring
Reduction
Partnership
(GGFR)

(http://www.worldbank.org/en/programs/gasflaringreduction), while dark green points show forest fires adopted from Hao et al. (2016). 